\title{
Noninvasive ventilation reduces energy expenditure in amyotrophic lateral sclerosis
}

\author{
Marjolaine Georges ${ }^{1,2,3,4}$, Capucine Morélot-Panzini ${ }^{1,2,3}$, Thomas Similowski ${ }^{1,2,3+}$ and Jesus Gonzalez-Bermejo ${ }^{1,2,3^{*+}}$
}

\begin{abstract}
Background: Amyotrophic lateral sclerosis (ALS) leads to chronic respiratory failure. Diaphragmatic dysfunction, a major driver of dyspnea and mortality, is associated with a shift of the burden of ventilation to extradiaphragmatic inspiratory muscles, including neck muscles. Besides, energy expenditure is often abnormally high in ALS, and this is associated with a negative prognostic value. We hypothesized that noninvasive ventilation (NIV) would relieve inspiratory neck muscles and reduce resting energy expenditure (REE).

Methods: Using indirect calorimetry, we measured REE during spontaneous breathing (REESB) and NIV (REE ALS patients with diaphragmatic dysfunction, during the first 3 months of NIV. Measured values were compared

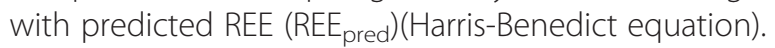

Results: NIV abolished inspiratory neck muscle activity. Even though our patients were not hypermetabolic, on the contrary, with a REE $E_{S B}$ that was lower than REE $E_{\text {pred }}$ (average 11\%), NIV did reduce energy expenditure. Indeed, median REE $E_{N I}$, in this population with a mean body mass index of $21.4 \mathrm{~kg} \cdot \mathrm{m}^{-2}$, was $1149 \mathrm{kcal} / 24 \mathrm{~h}$ [interquartile 970-1309], lower than $\operatorname{REE}_{S B}$ (1197 kcal/24 h, 1054-1402; mean difference 7\%; $p=0.03$, Wilcoxon). REE ${ }_{S B}$ and REE $E_{N I V}$ were correlated with forced vital capacity and maximal inspiratory pressure.

Conclusions: NIV can reduce energy expenditure in ALS patients probably by alleviating the ventilatory burden imposed on inspiratory neck muscles to compensate diaphragm weakness. It remains to be elucidated whether or not, in which population, and to what extent, NIV can be beneficial in ALS through the corresponding reduction in energy expenditure.
\end{abstract}

Keywords: Amyotrophic lateral sclerosis, Noninvasive ventilation, Energy expenditure, Diaphragm, Inspiratory neck muscles

\section{Background}

Amyotrophic lateral sclerosis (ALS) is a degenerative disease that affects motor neurones in the cerebral cortex, brainstem and spinal cord, with ensuing atrophy of skeletal muscles. Respiratory failure develops when respiratory motor neurones are involved. ALS-related respiratory failure causes major suffering and is a leading cause of death [1]. Mechanical ventilation, most often administered non-invasively (NIV), is currently the only treatment for ALS-related respiratory failure. It prolongs

\footnotetext{
*Correspondence: jesus.gonzalez@psl.aphp.fr

${ }^{\dagger}$ Equal contributors

'Sorbonne Universités, UPMC Univ Paris 06, UMR_S 1158 "Neurophysiologie Respiratoire Expérimentale et Clinique", F-75005 Paris, France

2INSERM, UMR_S 1158 "Neurophysiologie Respiratoire Expérimentale et Clinique", F-75005 Paris, France

Full list of author information is available at the end of the article
}

survival and improves quality of life [2]. Diaphragm weakness is a major determinant of ALS-related respiratory failure $[3,4]$.

A large proportion of ALS patients exhibit hypermetabolism [5-7], defined as an increase in resting energy expenditure (REE). Yet REE is a determinant of body weight and weight loss, that both have a documented negative prognostic impact in ALS [8-10].

Patients with ALS-related diaphragm weakness often exhibit strong phasic activity of inspiratory neck muscles the so-called "respiratory pulse" - [3]. These muscles can be abnormally powerful at producing negative intrathoracic pressures for inspiration [11]. This can be interpreted as a compensatory mechanism to maintain ventilation: in ALS patients with diaphragm paralysis, vital capacity (VC) is directly correlated with the inspiratory pressure 
generating capability of inspiratory neck muscles [11]. In some cases, the phasic inspiratory activity of neck muscles extends during rapid-eye-movement (REM) sleep [4]. There therefore appears to be a shift of the inspiratory burden from the diaphragm to inspiratory neck muscles when the ALS degenerative process involves the phrenic motoneurones.

We hypothesized that extradiaphragmatic inspiratory muscles including inspiratory neck muscles contribute to "resting" energy expenditure in ALS patients with diaphragm weakness. To test this hypothesis we compared resting energy expenditure (REE) in ALS patients during spontaneous breathing and under NIV.

\section{Methods \\ Patients}

This was an exploratory "proof of concept" study conducted in a convenience sample of 16 patients with probable or certain ALS according to the revised El Escorial criteria [12] (Table 1). The study was conducted in the Paris (France) ALS reference center, in a 1600-bed tertiary university hospital. This study was conducted in accordance with the amended Declaration of Helsinki. The appropriate French regulatory and ethical authority (Comité de Protection des Personnes Ile-de-France 6, La Pitié-Salpêtrière, Paris, decision \#102-12) approved the protocol, and written informed consent was obtained from all patients.

\section{Inclusion criteria}

To be eligible for inclusion in this study, patients had to have been placed on NIV indication defined according to current criteria, [13] for at least 24 hours and up to 3 months ( \pm 1 week). NIV had to be considered to be adequate, either immediately or after the first NIV adjustments [14]. Patients had to present signs of diaphragmatic dysfunction including respiratory pulse in the supine position.

\section{Non-inclusion criteria}

Patients with ALS in whom NIV had been started in an emergency context were not eligible. Patients with a disease other than ALS likely to alter nutritional status and metabolic status (renal failure, diabetes or thyroid disease, recent episode of acute respiratory failure, active infection, chronic pancreatitis, chronic alcoholism, corticosteroid therapy, known malignancy) could not be included in the study.

All in all, over the study period, 24 patients were eligible among 106 ALS patients seen at the center. Two of those refused to participate in the study, technical problems occurred in one case, and recordings were missed in 5 cases.
Table 1 Characteristics of ALS patients at initiation of ventilatory assistance and results of neurological and respiratory assessments

\begin{tabular}{|c|c|}
\hline Parameters & $\begin{array}{l}\text { Median } \\
{\left[1^{\text {st }}-3^{\text {rd }} \text { quartiles }\right]}\end{array}$ \\
\hline \multicolumn{2}{|l|}{ Anthropometric data } \\
\hline Age (years) & $68[56.5-73]$ \\
\hline Gender (male/female) & $12 / 4$ \\
\hline BMI $\left(\mathrm{kg} / \mathrm{m}^{2}\right)$ & $21.4[19.1-26.6]$ \\
\hline Smoking (yes/no) & $10 / 6$ \\
\hline \multicolumn{2}{|l|}{ Neurological assessment } \\
\hline ALS-FRS-R score & $31[26.5-35]$ \\
\hline Norris bulbar score & 35 [26.2-38] \\
\hline \multicolumn{2}{|l|}{ Respiratory assessment } \\
\hline Dyspnea score on MMRC scale & $3[1-3.5]$ \\
\hline $\begin{array}{l}\text { Inspiratory contraction of inspiratory neck } \\
\text { muscles during quiet breathing in supine } \\
\text { position (yes/no) }\end{array}$ & $16 / 0$ \\
\hline $\begin{array}{l}\text { Inspiratory contraction of inspiratory neck } \\
\text { muscles during indirect calorimetry in sitting } \\
\text { position (yes/no) }\end{array}$ & $11 / 5$ \\
\hline $\mathrm{PaCO}_{2}(\mathrm{mmHg})$ & $45[42.5-48]$ \\
\hline $\mathrm{PaO}_{2}(\mathrm{mmHg})$ & $73[66.5-77.5]$ \\
\hline Bicarbonate (mmol/l) & $28[27-29.5]$ \\
\hline $\begin{array}{l}\text { Time spent with } \mathrm{SpO}_{2}<90 \% \\
\text { (\% of recording time) }\end{array}$ & $30[6.2-72]$ \\
\hline FVC sitting (ml) & 1990 [1140-2045] \\
\hline FVC sitting (\% predicted) & $47[35-54]$ \\
\hline FVC supine (ml) & 1650 [847-2182] \\
\hline FVC supine (\% predicted) & $38.5[30-58]$ \\
\hline $\mathrm{Pi}_{\text {MAX }}\left(\mathrm{cmH}_{2} \mathrm{O}\right)$ & 31 [19.7-58.2] \\
\hline $\mathrm{Pi}_{\text {MAX }}(\%$ predicted $)$ & 37 [19.5-55.2] \\
\hline SNIP $\left(\mathrm{cmH}_{2} \mathrm{O}\right)$ & $32[16.5-40.2]$ \\
\hline SNIP (\% predicted) & $39[23.2-42.7]$ \\
\hline
\end{tabular}

Abbreviations: ALS-FRS-R revised Amyotrophic Lateral Sclerosis - Functional Rating Scale, $B M I$ Body Mass Index, FVC Forced Vital Capacity, $\mathrm{PaO}_{2}$ arterial oxygen tension, $\mathrm{PaCO}_{2}$ arterial carbon dioxide tension, $\mathrm{Pi}_{M A X}$ maximal inspiratory mouth pressure (measured from functional residual capacity; best of three maneuvers; data missing in 5 patients), SNIP Sniff Nasal Inspiratory Pressure (measured from functional residual capacity; best of ten maneuvers; data missing in 1 patients - in whom MIP was available-), $\mathrm{SpO}_{2}$ transcutaneous pulsed oxygen saturation.

Dyspnea was evaluated using the Modified Medical Research Council (MMRC) scale.

Grade 0: I only get breathless with strenuous exercise.

Grade 1: I get short of breath when hurrying on the level or walking up a slight hill. Grade 2: I walk slower than people of the same age on the level because of breathlessness or have to stop for breath when walking at my own pace on the level.

Grade 3: I stop for breath after walking about 100 yards or after a few minutes on the level.

Grade 4: I am too breathless to leave the house or I am breathless when dressing.

\section{Assessments}

Neurological, respiratory and metabolic assessments were all performed on the same day. 


\section{Neurological assessment}

The severity of the neurological deficit was evaluated by the revised ALS Functional Rating Scale (ALS-FRS-R), which rates the ability to perform activities of daily living from 0 (total inability) to 48 points (no limitation) and incorporates respiratory items (dyspnea, orthopnea, respiratory insufficiency). The bulbar section of the Norris scale was used to quantify bulbar impairment from 0 (no bulbar function) to 39 points (normal bulbar function). The date of onset of the symptoms and their initial level (bulbar or spinal), the date of confirmation of the diagnosis, and ongoing treatments (all patients received treatment with riluzole $50 \mathrm{mg}$, twice daily) were also recorded.

\section{Respiratory assessment}

Respiratory function was evaluated by arterial blood gases with spontaneous breathing in room air and by overnight pulse oximetry $\left(\mathrm{SpO}_{2}\right)$ recording. Forced Vital Capacity (FVC) was measured in the supine and sitting positions with the EasyOne $e^{\oplus}$ ultrasound spirometer (NDD Medical Technologies, Andover, MA, USA). Inspiratory muscle strength was evaluated by measuring the maximal inspiratory pressure at the mouth $\left(\mathrm{Pi}_{\mathrm{MAX}}\right)$ and at the nostril ("sniff nasal inspiratory pressure", SNIP) using a Micro-RPM ${ }^{\bullet}$ digital manometer (Micro Medical, Chatham, Kent, UK).

Optimization of nocturnal NIV was verified by arterial blood gases performed in the morning, one hour after disconnecting the ventilator, nocturnal $\mathrm{SpO}_{2}$ recording on NIV and detection of leakages by the software integrated into the ventilator $[14,15]$. Of note, all the patients were equipped with home ventilators of the same make and model (Stellar ${ }^{\oplus}$, Resmed, Bella Vista, Australia), with the spontaneous-timed pressure support mode (inspiratory and expiratory trigger).

\section{Nutritional assessment}

Nutritional assessment comprised measurement of height and weight for calculation of body mass index (BMI), by adopting a cut-off of $20 \mathrm{~kg} / \mathrm{m}^{2}$ for malnutrition. Resting energy expenditure (REE) was measured by indirect calorimetry using a Quark $\mathrm{RMR}^{\mathrm{T}}$ apparatus (Cosmed, Rome, Italy). Measurements were performed before 10 o'clock in the morning after fasting overnight and after resting for 20 minutes in a semi-sitting position in a quiet room heated to between $20^{\circ} \mathrm{C}$ and $24^{\circ} \mathrm{C}$. Only values obtained at metabolic steady-state (less than $5 \%$ changes in $\mathrm{V}^{\prime} \mathrm{O}_{2}, \mathrm{~V}^{\prime} \mathrm{CO}_{2}$ and $\mathrm{RQ}$ for at least 15 minutes) were taken into account.

During spontaneous breathing on room air $\left(\mathrm{REE}_{\mathrm{SB}}\right)$, oxygen consumption $\left(\mathrm{V}^{\prime} \mathrm{O}_{2}\right)$ and $\mathrm{CO}_{2}$ production $\left(\mathrm{V}^{\prime} \mathrm{CO}_{2}\right)$ were measured by a sensor fitted to the tip of a close-fitting oronasal mask. During NIV (REE NIV), inspired air is carried from the respirator to the mask via a single tube. Expired air is delivered into the chamber via a calibrated leak distal to the sensor measuring $\mathrm{V}^{\prime} \mathrm{O}_{2}$ and $\mathrm{V}^{\prime} \mathrm{CO}_{2}$ (Figure 1). This methodology was developed in several healthy subjects prior to the study to ensure that measurement of REE on spontaneous breathing by the canopy method was equivalent to the that obtained by the cycle-to-cycle gas analyzer and that the calibrated leak in the NIV circuit did not induce any reduction of REE.

Predicted REE ( $\mathrm{REE}_{\text {pred }}$ ) was also calculated by the equation of Harris and Benedict [16]:

for males, $\mathrm{REE}=66+1.38^{*}$ weight $(\mathrm{kg})+5^{*}$ height $(\mathrm{cm})$ 6.8 *age(years)

for females, $\quad$ REE $=655+9.7^{*}$ weight $(\mathrm{kg})+1.8$ "height (cm)-4.7*age(years).

\section{Statistical analysis}

Results were expressed as the median [1st quartile; 3rd quartile], and nonparametric tests were used for statistical analysis. REE measured on spontaneous breathing was compared to the predicted value by a Wilcoxon's test, which was also used to compare REE $\mathrm{NIV}_{\text {and }}$ REE $\mathrm{SB}_{\mathrm{SB}}$. Correlations between metabolic status $\left(\mathrm{REE}_{\mathrm{SB}}, \mathrm{REE}_{\mathrm{NIV}}\right.$, $\left.R E E_{\text {pred }}-R E E_{S B}, R E E_{S B}-R E E_{N I V}\right)$ and the various parameters likely to influence metabolic status were analyzed by Spearman's rank correlation. The limit of significance was $5 \%(\mathrm{P}<0.05)$.

\section{Results}

Measurements were performed after the first night on NIV in 10 cases, and at later time-points in 6 cases (after 32 to 96 nights). The anthropometric characteristics of the patients included in the study and the results of their respiratory and neurological assessments are summarized in Table 1 . Thirty-one per cent $(5 / 16)$ of patients presented an initially bulbar form of ALS. No patient has a gastrostomy. The first neurological symptoms had been present for an average of 26.5 [14; 39.2] months. All patients had received treatment with riluzole for an average of $13.2[6.7 ; 19.5]$ months. At the time of the assessment, $37 \%(6 / 16)$ of patients had a BMI $<20 \mathrm{~kg} / \mathrm{m}^{2}$ and $50 \%(8 / 16)$ of patients reported weight loss greater than $10 \%$ since onset of the disease. None of the patients had had a percutaneous endoscopic gastrostomy at the time of the procedure, but 6 of them (all among those who had lost weight) underwent this procedure in the following weeks.

$\mathrm{REE}_{\mathrm{SB}}$ was significantly lower than $\mathrm{REE}_{\text {pred }}$ (1197.3 [1054.7; 1402.6] kcal/24 h vs 1389.5 [1193.9; 1622.6] $\mathrm{kcal} / 24 \mathrm{~h}, \mathrm{p}=0.004)$. The mean $\mathrm{REE}_{\mathrm{SB}} / \mathrm{REE}_{\text {pred }}$ ratio was 90 [83; 97]\%, with only one patient presenting a $\mathrm{REE}_{\mathrm{SB}} / \mathrm{REE}_{\text {pred }}$ ratio greater than 110\% (111\%). 


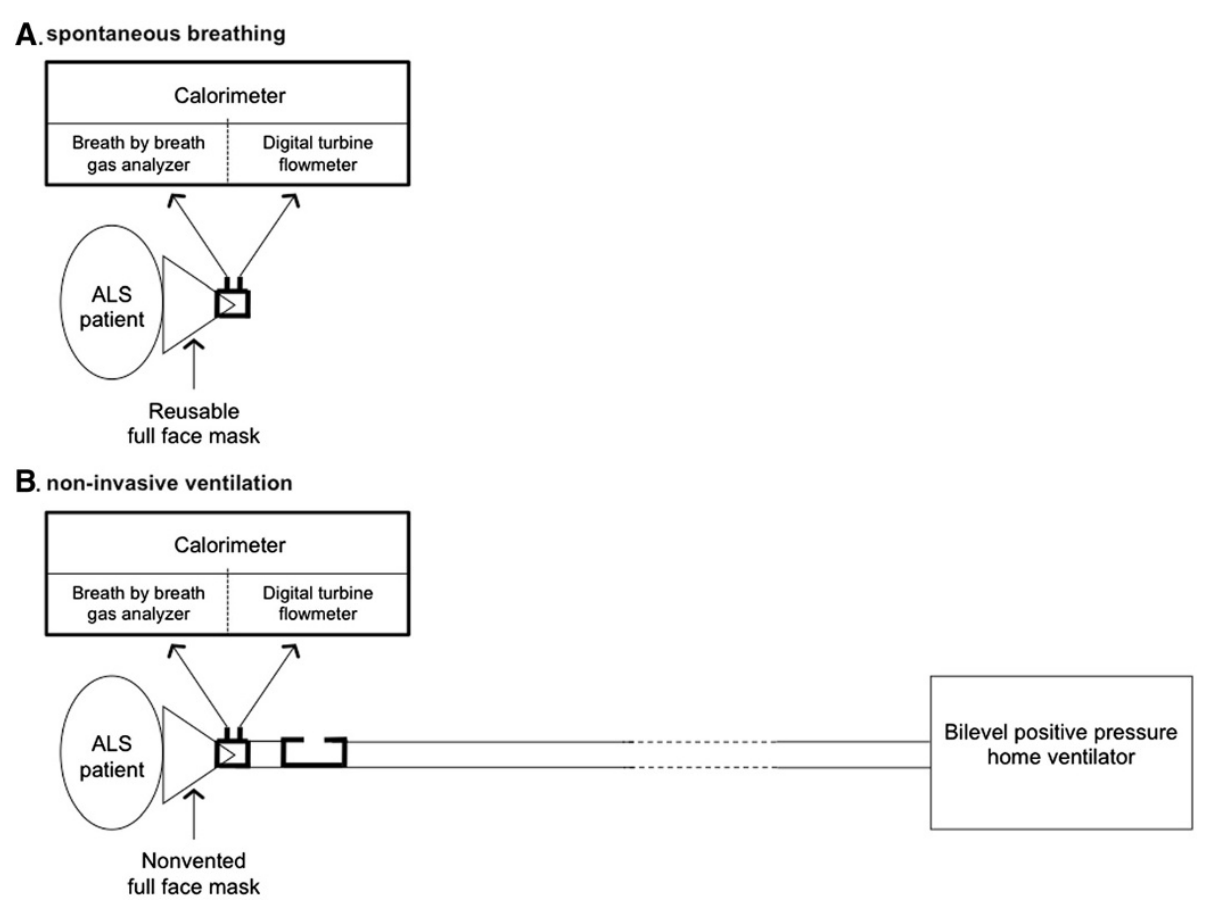

Figure 1 Schematic representation of measurement of energy expenditure during spontaneous breathing (A) and noninvasive ventilation (B).

Ventilation was increased on NIV, with correction of diurnal and nocturnal alveolar hypoventilation (Table 2). All patients reported complete or almost complete relief of dyspnea. Physical examination demonstrated that inspiratory neck muscle activity was abolished in every case.

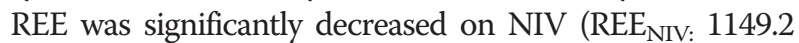
[970.8; 1309.5] $\mathrm{kcal} / 24 \mathrm{~h}, \mathrm{p}=0.03$ compared to $\mathrm{REE}_{\mathrm{SB}}$; $\mathrm{REE}_{\mathrm{SB}}-\mathrm{REE}_{\mathrm{NIV}}-78.1[-186.2 ;-27.5] \mathrm{kcal} / 24 \mathrm{~h}$, i.e. by -7

Table 2 Evaluation of ventilatory variables on noninvasive ventilation

\begin{tabular}{|c|c|c|c|}
\hline & $\begin{array}{l}\text { Spontaneous } \\
\text { breathing in } \\
\text { room air }\end{array}$ & $\begin{array}{l}\text { Noninvasive } \\
\text { ventilation median } \\
{\left[1^{\text {st }}-3^{\text {rd }} \text { quartiles }\right]}\end{array}$ & p-value \\
\hline $\mathrm{VT}(\mathrm{ml})$ & 406.8 [289.5-486.8] & $535.7[450.8-578.4]$ & 0.003 \\
\hline $\mathrm{RF}(/ \min )$ & $17.6[14.7-23.9]$ & 15.4 [14.5-18.4] & 0.02 \\
\hline Ventilation (I/min) & $7.1[6.5-7.9]$ & $8.3[7.5-9.9]$ & $<0.001$ \\
\hline $\mathrm{PaCO} 2(\mathrm{mmHg})(\mathrm{n}=12)^{*}$ & $47[43-48]$ & $41.5[38-44]$ & 0.002 \\
\hline $\mathrm{PaO} 2(\mathrm{mmHg})(\mathrm{n}=12)^{*}$ & $69[65.7-75.2]$ & $88.5[70-97.5]$ & 0.005 \\
\hline $\begin{array}{l}\text { A-a gradient }(\mathrm{mmHg}) \\
(\mathrm{n}=12)^{*}\end{array}$ & $23.1[16.6-27.6]$ & $9.2[3.9-29.3]$ & 0.03 \\
\hline $\operatorname{VD}(m l)(n=12)^{*}$ & 117.7 [78.2-141.6] & 178.9 [152.6-211.8] & 0.01 \\
\hline $\begin{array}{l}\text { Time spent with } \\
\mathrm{SpO}_{2}<90 \% \\
\text { (\% of recording time) }\end{array}$ & $30[6.2-72]$ & $1[1-3]$ & $<0.001$ \\
\hline
\end{tabular}

Abbreviations: $\mathrm{A}$-a gradient for Alveolar-arterial gradient, $\mathrm{PaO}_{2}$ arterial oxygen tension, $\mathrm{PaCO}_{2}$ arterial carbon dioxide tension, $\mathrm{RF}$ Respiratory Frequency, $\mathrm{SpO}_{2}$ transcutaneous pulsed oxygen saturation, $V T$ for tidal volume, $V D$ dead space volume (calculated using Bohr formula, note that non invasive ventilation efficiently corrects $\mathrm{PaCO} 2$ in spite of an increased VD -expected-).
$[-14 ;-2] \%$ (Figure 2). There was no difference in the magnitude of this result between the 10 patients studied immediately after NIV initiation and the 6 patients studied later.

$\mathrm{REE}_{\mathrm{SB}}$ and $\mathrm{REE}_{\mathrm{NIV}}$ were significantly correlated with gender, the Norris bulbar score, sitting FVC and $\mathrm{Pi}_{\mathrm{MAX}}$ (Table 3). There was no other correlation with any of the anthropometric (BMI, age), respiratory or neurological (severity, history of disease) variables. The $\mathrm{REE}_{\mathrm{SB}}-\mathrm{REE}_{\mathrm{NIV}}$ difference did not correlate with any of the collected variables.

\section{Discussion}

This study shows that NIV can acutely decrease resting energy expenditure in ALS patients with ALS-related chronic respiratory insufficiency exhibiting signs of severe diaphragmatic dysfunction.

\section{Study limitations}

For the purposes of this proof-of-concept study, we deliberately selected a small number of patients who were as homogeneous as possible in terms of the respiratory impact of ALS. Apart from NIV criteria, all patients exhibited obvious signs of diaphragmatic dysfunction including increased activity of inspiratory neck muscles, which may limit extrapolation of our results. Of note, the diagnosis of diaphragmatic dysfunction was based on physical examination and phrenic nerve stimulation was not performed to measure diaphragm strength and to distinguish lower from 


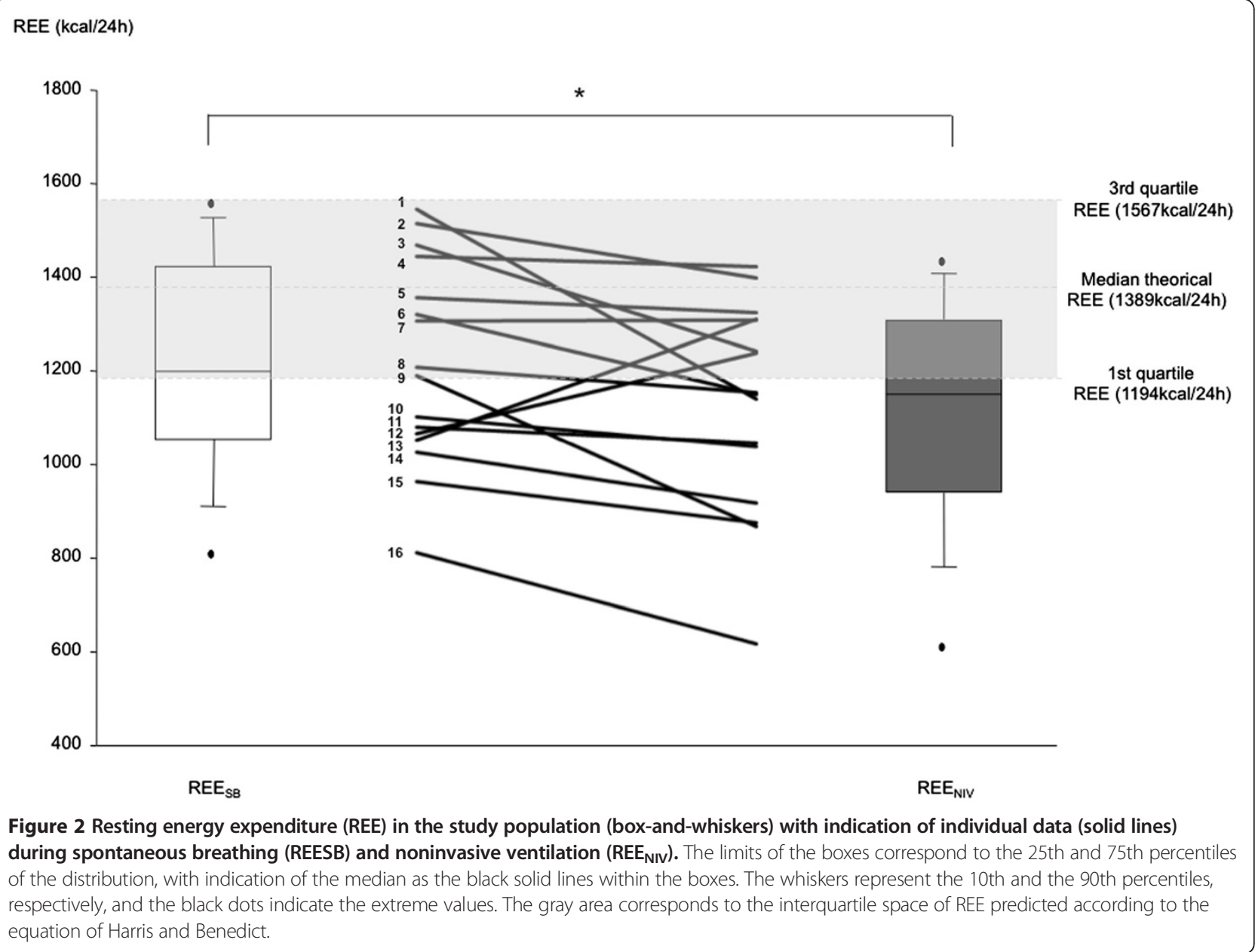

upper respiratory motor neurone diseases [3]. Silencing of inspiratory neck muscles by NIV was also not confirmed by electromyography (but only clinically). If anything, residual inspiratory neck muscle activity would have underestimated the effect of NIV on energy expenditure. Similarly, the patients were studied under a triggered NIV modality: controlled mechanical ventilation could have resulted in a larger reduction of REE. Measurement errors with indirect calorimetry are a major concern, particularly when comparing two conditions involving different setups. We took extensive precautions to control for technical issues that could have interfered with the measurements, and extensive preliminary measurements were performed in normal subjects to check that REE was not affected by the different setups. The difference between $\mathrm{REE}_{\mathrm{SB}}$ and $\mathrm{REE}_{\mathrm{NIV}}$ in our patients (median 7\%) exceeded the coefficient of variation of the measurement reported by other authors under similar conditions 3.5\% $\pm 2.7 \%$-standard error- in stable mechanically ventilated patients, see [17] and was also greater than the variability observed in normal subjects during our in-house preliminary experiments.

Table 3 Significant correlations between resting energy expenditure and gender, Norris bulbar score, forced vital capacity and maximal inspiratory mouth pressure

\begin{tabular}{llllll}
\hline & REE $_{\text {SB }}$ & & REE $_{\text {NIV }}$ & & REE $_{\text {SB }}-\mathbf{R E E}_{\text {NIV }}$ \\
\hline Gender & $0.523^{*} 0.037-0.809$ & 0.038 & $0.714^{*} 0.337-0.893$ & 0.001 & $0.282-0.248 ; 0.683$ \\
Norris bulbar score & $0.582^{*} 0.099-0.843$ & 0.023 & $0.677^{*} 0.253-0.883$ & 0.005 & $0.157-0.386 ; 0.620$ \\
FVC sitting (ml) & $0.577^{*} 0.038-0.856$ & 0.039 & $0.635^{*}-0.022-0.821$ & 0.019 & $0.079-0.494 ; 0.604$ \\
Pi $_{\text {MAX }}\left(\mathrm{cmH}_{2} \mathrm{O}\right)$ & $0.826^{*} 0.359-0.962$ & 0.006 & $0.707^{*} 0.080-0.933$ & 0.033 & $-0.044-0.688 ; 0.639$ \\
\hline
\end{tabular}

REE, resting energy expenditure; "sb", during spontaneous breathing; "niv", during non invasive ventilation.

FVC, Forced Vital Capacity; $\mathrm{Pi}_{\mathrm{MAX}}$, maximal inspiratory mouth pressure. 


\section{Comparison with available data}

REE and mechanical ventilation: the energy cost of breathing

The contribution of respiratory muscles to REE or oxygen consumption at rest has been estimated in the literature to be between $1 \%[18,19]$ and $5-7 \%$ in normal individuals [20-23] and in quadriplegics [24]. These estimates were mostly based on back-extrapolations of the relationship between $\mathrm{V}^{\prime} \mathrm{O} 2$ and load-induced increases in the work of breathing [25]. This relationship is not linear and can underestimate the oxygen cost of unloaded breathing. To avoid this bias, the energy cost of breathing can be derived from comparisons between energy expenditure measured during spontaneous breathing and during mechanical ventilation in the same individuals [26,27]. This approach implies that respiratory muscles are actually passive during the measurements performed under mechanical ventilation, which is not always easy to ascertain. In patients with chronic obstructive pulmonary disease receiving NIV, Hugli et al. [28] estimated that respiratory $\mathrm{V}^{\prime} \mathrm{O}_{2}$ was an average of $1.6 \%$ of $\mathrm{V}^{\prime} \mathrm{O}_{2}$. This figure was underestimated because NIV mostly failed to abolish respiratory muscle electromyographic activity. In addition, the ventilation-induced reduction in $\mathrm{V}^{\prime} \mathrm{O}_{2}$ was not normally distributed $(1.6 \pm 6 \%)$ and some patients had respiratory $\mathrm{V}^{\prime} \mathrm{O}_{2}$ values of about $10 \%$ of $\mathrm{V}^{\prime} \mathrm{O}_{2}$ [28]. In quadriplegic patients treated with phrenic stimulation, switching ventilatory assistance from controlled mechanical ventilation to diaphragm pacing increased REE by an average of $21 \%$ [29]. Because the patients in this study were overventilated, their respiratoryrelated energy expenditure was probably artefactually high. Hyperventilation-corrected values fell in the 10-15\% range. To the best of our knowledge, the study with the most similar design to the present study compared energy expenditure during spontaneous breathing and mechanical ventilation in 9 tracheotomized patients with post-polio chronic respiratory failure [30]. In these patients, REE decreased from 1378 (958-1607) kcal/24 h during spontaneous breathing to 1086 (598-1579) $\mathrm{kcal} / 24 \mathrm{~h}$ during pressure support ventilation (22\%), and $\mathrm{V}^{\prime} \mathrm{O}_{2}$ decreased from $207(141-235) \mathrm{ml} / \mathrm{min})$ to 159 (92-230)(23\%). The REE reduction observed during NIV in our ALS patients (median 7\%) and it $\mathrm{V}^{\prime} \mathrm{O}_{2}$ counterpart are therefore in the upper range of available normal values for respiratory $\mathrm{V}^{\prime} \mathrm{O}_{2}$ and in the lower range of reported values in patients. In addition to the possible underestimation discussed above, it must be emphasized that our patients mostly depended on their inspiratory neck muscles to breathe, as their diaphragm did not participate in ventilation.

\section{REE in ALS}

In our patients, $\mathrm{REE}_{\mathrm{SB}}$ was on average $10 \%$ lower than the value predicted by the Harris and Benedict equation. Of note, in the literature the prediction error for the Harris-Benedict equation has been reported to be as high as $18.6+14.9 \%$, with limits of agreement showing that this equation could overestimate caloric expenditure by $591 \mathrm{kcal} / \mathrm{d}$ and underestimate requirements by $677 \mathrm{kcal} / \mathrm{d}$ $[31,32]$. The energy requirements in ALS is a complex issue see review in [33] and the details are beyond the scope of this discussion. Some studies have shown that one-half to two-thirds of ALS patients can be described as "hypermetabolic" [5-7] and remain so throughout the course of the disease [5]. In comparison with these studies, our patients had a slightly lower BMI, which, although fat-free mass was not measured, tends to suggest that they were somewhat malnourished. More importantly, the respiratory status of our patients was poorer than that reported in other studies, as our study appears to be the first to provide REE measurements during spontaneous breathing in ALS patients meeting the criteria for mechanical ventilation (Ellis and Rosenfeld measured REE in ALS patients requiring NIV, but it is unclear from their article whether the measurements were obtained during spontaneous breathing or under NIV)[32]. Our patients had a mean FVC of $42.7 \pm 5.9 \%$ when $\mathrm{REE}_{\mathrm{SB}}$ was determined, compared with a mean FVC close to $80 \%$ in the studies by Desport et al. [6,7]. In the longitudinal study by Bouteloup et al. [5], the 28 patients with sequential REE measurements had a mean $\mathrm{VC}$ of $67 \%$ at the time of the last measurement. In the longitudinal study by Kasarkis et al [34], performed before the NIV era, some patients were and remained hypermetabolic during the course of the disease, but the lowest observed FVC in this population was greater than $50 \%$. It is therefore possible that the development of respiratory insufficiency in ALS has a masking effect on hypermetabolism, as suggested by Vaisman et al. [35]. This could occur via various mechanisms, including increasing malnutrition [33,35] due to the combination of ALS-related impairment of swallowing and/or eating-related dyspnea [36], as described in other types of severe chronic respiratory insufficiency $[37,38]$. Of note, energy expenditure in ventilated ALS patients has been found to be low $[8,39]$, with results comparable to those observed in ventilator-dependent Duchenne patients [40], but it has also been found to be increased. Sherman et al. observed hypermetabolism in ventilated patients [31], and Ellis and Rosenfeld observed moderately increased REE values in patients requiring NIV [32]. In both cases, mean BMI values were about $25 \mathrm{~kg} \cdot \mathrm{m}^{-2}$, vs. 22 in our patients, which might explain the discordant results. In any case, the present study showed that REE decreased under NIV in patients who were not hypermetabolic but who tended to be hypometabolic (possibly because of some degree or malnutrition): the amount of energy expenditure spared by NIV would probably have been even greater in better nourished patients. Also worthy of notice, the effect of NIV on REE was quite heterogeneous in our patients (Figure 2). We did not evidence any 
particular explanation for this finding. The reduction in REE was similar in the 10 patients studied upon NIV initiation and in the 6 patients studied somewhat later, and the correction of hypoventilation was excellent and homogeneous in the study population (Table 2). In addition, the REE response to NIV did not correlate with any of the anthropometric, respiratory or neurological variables collected.

\section{Conclusions}

There is a general consensus that NIV prolongs survival and improves quality of life in ALS patients, and particularly those without severe bulbar dysfunction. These positive outcomes are implicitly attributed to the correction of hypoventilation and nocturnal desaturations, and to the relief of dyspnea. In the light of the present observations, it might be hypothesized that NIV could also be beneficial, in certain cases, by reducing energy expenditure and therefore contributing to a better nutritional equilibrium -the prognostic value of which has been established-. Data from Lechtzin et al. [41] have suggested that starting NIV early in the course of respiratory involvement can be associated with improved survival (an average gain of one year in a population with a mean FVC of $74.3 \pm 10.1 \%$ pred absence of obvious respiratory insufficiency-, in comparison with a population with a mean FVC of $48.3 \pm 11.3 \%$ pred). These results must be taken with caution because they have not been prospectively corroborated and could, at least in part, be due to a time bias effect. However, our observations point at a putative mechanism for a beneficial effect of early NIV, namely a reduced respiratory-related energy expenditure. Of note, the accelerated muscle wasting due to hypermetabolism is bound to involve respiratory muscles. A NIV-related reduction in energy expenditure could therefore theoretically contribute to slow respiratory decline, yet a recent retrospective study suggested, apparently for the first time, that NIV could indeed decrease the ALS-related decline of VC [42]. The correlation observed between REE and FVC and $\mathrm{Pi}_{\mathrm{MAX}}$ in our patients (Table 3) tends to supports this hypothesis. Nevertheless, NIV may prove difficult to implement in asymptomatic patients. Proposing "early NIV" with the purpose of reducing energy expenditure would require prior convincing documentation of the corresponding clinical benefits. Further studies are therefore needed to elucidate what determines the response of REE to NIV and whether, in what particular population, and to what extent, early NIV can be beneficial in ALS through a reduction in respiratory-related energy expenditure. The role of ventilatory mode and triggering modalities is among the factors to be studied.

\section{Abbreviations}

ALS: Amyotrophic lateral sclerosis; ALS-FRS-R revised: ALS functional rating scale; BMI: Body mass index; FCV: Forced vital capacity; INM: Inspiratory neck muscles; NIV: Noninvasive ventilation; $\mathrm{Pi}_{\text {MAx: }}$ Maximal inspiratory pressure; REE: Resting energy expenditure; $\mathrm{REE}_{\mathrm{SB}}$ : REE measured during spontaneous breathing; REE $E_{N I V}$ : REE measured during noninvasive ventilation; REE $E_{\text {pred: }}$ Predicted REE according to the Harris and Benedict equation; REM: Rapid eye movement sleep; SNIP: Sniff nasal inspiratory pressure; $\mathrm{SpO}_{2}$ : Pulsed oximeter oxygen saturation; $\mathrm{V}^{\prime} \mathrm{CO}_{2}$ : Carbon dioxide production; $\mathrm{V}^{\prime} \mathrm{O}_{2}$ : Oxygen consumption.

\section{Competing interests}

This study did not involve any competing interest, financial or otherwise, for any of the authors.

\section{Authors' contributions}

MG participated in the conception and design of the study, performed most of data collection and analysis, participated in data interpretation, drafted the submitted article and approved the final submission. CMP participated in the conception and design of the study, contributed to data analysis and data interpretation, revised the manuscript and approved the final submission. TS participated in the conception and design of the study, contributed to data analysis and data interpretation, revised the manuscript and approved the final submission. JGB participated in the conception and design of the study, contributed to data collection, data analysis and data interpretation, revised the manuscript and approved the final submission.

\section{Acknowledgements}

This study was funded in part by the non profit "Association pour le Développement et l'Organisation de la Recherche en Pneumologie et sur le Sommeil, Paris, France" and benefited from the support of the program "Investissement d'Avenir ANR-10-AlHU-06" of the French Government. The authors are grateful to Anthony Saul for editing the English style and grammar of the manuscript.

\section{Author details}

${ }^{1}$ Sorbonne Universités, UPMC Univ Paris 06, UMR_S 1158 "Neurophysiologie Respiratoire Expérimentale et Clinique", F-75005 Paris, France. ${ }^{2}$ INSERM, UMR_S 1158 "Neurophysiologie Respiratoire Expérimentale et Clinique", F-75005 Paris, France. ${ }^{3}$ AP-HP, Groupe Hospitalier Pitié-Salpêtrière Charles Foix, Service de Pneumologie et Réanimation Médicale (Département "R3S"), F-75013 Paris, France. ${ }^{4}$ Centre Hospitalier Universitaire de Dijon, Service de Pneumologie et Réanimation Respiratoire, Dijon, France.

Received: 8 November 2013 Accepted: 3 February 2014

Published: 7 February 2014

\section{References}

1. Gil J, Funalot B, Verschueren A, Danel-Brunaud V, Camu W, Vandenberghe N, Desnuelle C, Guy N, Camdessanche JP, Cintas P, et al: Causes of death amongst French patients with amyotrophic lateral sclerosis: a prospective study. Eur J Neurol 2008, 15:1245-1251.

2. Bourke SC, Tomlinson M, Williams TL, Bullock RE, Shaw PJ, Gibson GJ: Effects of non-invasive ventilation on survival and quality of life in patients with amyotrophic lateral sclerosis: a randomised controlled trial. Lancet Neurol 2006, 5:140-147.

3. Similowski T, Attali V, Bensimon G, Salachas F, Mehiri S, Arnulf I, Lacomblez L, Zelter M, Meininger V, Derenne JP: Diaphragmatic dysfunction and dyspnoea in amyotrophic lateral sclerosis. Eur Respir J 2000, 15:332-337.

4. Arnulf I, Similowski T, Salachas F, Garma L, Mehiri S, Attali V, Behin-Bellhesen V, Meininger $V$, Derenne JP: Sleep disorders and diaphragmatic function in patients with amyotrophic lateral sclerosis. Am J Respir Crit Care Med 2000, 161:849-856.

5. Bouteloup C, Desport JC, Clavelou P, Guy N, Derumeaux-Burel H, Ferrier A, Couratier P: Hypermetabolism in ALS patients: an early and persistent phenomenon. J Neurol 2009, 256:1236-1242.

6. Desport JC, Preux PM, Magy L, Boirie Y, Vallat JM, Beaufrere B, Couratier P: Factors correlated with hypermetabolism in patients with amyotrophic lateral sclerosis. Am J Clin Nutr 2001, 74:328-334.

7. Desport JC, Torny F, Lacoste M, Preux PM, Couratier P: Hypermetabolism in ALS: correlations with clinical and paraclinical parameters. Neurodegener Dis 2005, 2:202-207.

8. Shimizu T, Nagaoka U, Nakayama Y, Kawata A, Kugimoto C, Kuroiwa Y, Kawai M, Shimohata T, Nishizawa M, Mihara B, et al: Reduction rate of body mass index predicts prognosis for survival in amyotrophic lateral 
sclerosis: a multicenter study in Japan. Amyotroph Lateral Scler 2012, 13:363-366.

9. Clavelou P, Blanquet M, Peyrol F, Ouchchane L, Gerbaud L: Rates of progression of weight and forced vital capacity as relevant measurement to adapt amyotrophic lateral sclerosis management for patient Result of a French multicentre cohort survey. J Neurol Sci 2013, 331:126-131.

10. Korner S, Hendricks M, Kollewe K, Zapf A, Dengler R, Silani V, Petri S: Weight loss, dysphagia and supplement intake in patients with amyotrophic lateral sclerosis (ALS): impact on quality of life and therapeutic options. BMC Neurol 2013, 13:84.

11. Attali V, Mehiri S, Straus C, Salachas F, Arnulf I, Meininger V, Derenne JP, Similowski T: Influence of neck muscles on mouth pressure response to cervical magnetic stimulation. Am J Respir Crit Care Med 1997, 156:509-514.

12. Brooks BR, Miller RG, Swash M, Munsat TL: El Escorial revisited: revised criteria for the diagnosis of amyotrophic lateral sclerosis. Amyotroph Lateral Scler Other Motor Neuron Disord 2000, 1:293-299.

13. Andersen PM, Borasio GD, Dengler R, Hardiman O, Kollewe K, Leigh PN, Pradat PF, Silani $V$, Tomik B: EFNS task force on management of amyotrophic lateral sclerosis: guidelines for diagnosing and clinical care of patients and relatives. Eur J Neurol 2005, 12:921-938.

14. Gonzalez-Bermejo J, Morelot-Panzini C, Arnol N, Meininger V, Kraoua S, Salachas F, Similowski T: Prognostic value of efficiently correcting nocturnal desaturations after one month of non-invasive ventilation in amyotrophic lateral sclerosis: a retrospective monocentre observational cohort study. Amyotroph Lateral Scler Frontotemporal Degener 2013, 14:373-379.

15. Gonzalez-Bermejo J, Perrin C, Janssens JP, Pepin JL, Mroue G, Leger P, Langevin B, Rouault S, Rabec C, Rodenstein D: Proposal for a systematic analysis of polygraphy or polysomnography for identifying and scoring abnormal events occurring during non-invasive ventilation. Thorax 2012, 67:546-552.

16. Harris J, Benedict F: A biometric study of basal metabolism in man. Proc Natl Acad Sci 1918, 4:370-373.

17. Sundstrom M, Tjader I, Rooyackers $\mathrm{O}$, Wernerman J: Indirect calorimetry in mechanically ventilated patients. A systematic comparison of three instruments. Clin Nutr 2013, 32:118-121.

18. Cournand A, Richards DW Jr, Bader RA, Bader ME, Fishman AP: The oxygen cost of breathing. Trans Assoc Am Phys 1954, 67:162-173.

19. Silver JR: The oxygen cost of breathing in tetraplegic patients. Paraplegia 1963, 17:204-214.

20. Bartlett RG Jr, Brubach HF, Specht H: Oxygen cost of breathing. J Appl Physiol 1958, 12:413-424

21. Campbell EJ, Westlake EK, Cherniack RM: Simple methods of estimating oxygen consumption and efficiency of the muscles of breathing. J Appl Physio/ 1957, 11:303-308

22. Dodd DS, Yarom J, Loring SH, Engel LA: O2 cost of inspiratory and expiratory resistive breathing in humans. J Appl Physiol 1988, 65:2518-2523.

23. Margaria R, Milic-Emili G, Petit JM, Cavagna G: Mechanical work of breathing during muscular exercise. J Appl Physiol 1960, 15:354-358.

24. Manning H, McCool FD, Scharf SM, Garshick E, Brown R: Oxygen cost of resistive-loaded breathing in quadriplegia. J Appl Physiol 1992, 73:825-831.

25. Liljestrand G: Untersechungen uber die atmungsarbeit. Scan Arch Physiol 1918, 35:199-293.

26. Thung N, Herzog P, Christlieb II, Thompson WM Jr, Dammann JF Jr: The cost of respiratory effort in postoperative cardiac patients. Circulation 1963, 28:552-559.

27. Wilson RS, Sullivan SF, Malm JR, Bowman FO Jr: The oxygen cost of breathing following anesthesia and cardiac surgery. Anesthesiology 1973, 39:387-393.

28. Hugli O, Schutz Y, Fitting JW: The cost of breathing in stable chronic obstructive pulmonary disease. Clin Sci (Lond) 1995, 89:625-632.

29. Gonzalez-Bermejo J, Morelot-Panzini C, Georges M, Demoule A, Similowski T: Can diaphragm pacing improve gas exchange? Insights from quadriplegic patients. Eur Respir J 2014, 43:303-306

30. Barle H, Soderberg P, Haegerstrand C, Markstrom A: Bi-level positive airway pressure ventilation reduces the oxygen cost of breathing in long-standing post-polio patients on invasive home mechanical ventilation. Acta Anaesthesiol Scand 2005, 49:197-202.

31. Sherman MS, Pillai A, Jackson A, Heiman-Patterson T: Standard equations are not accurate in assessing resting energy expenditure in patients with amyotrophic lateral sclerosis. JPEN J Parenter Enteral Nutr 2004, 28:442-446.

32. Ellis $A C$, Rosenfeld J: Which equation best predicts energy expenditure in amyotrophic lateral sclerosis? J Am Diet Assoc 2011, 111:1680-1687.
33. Weijs PJ: Hypermetabolism, is it real? The example of amyotrophic lateral sclerosis. J Am Diet Assoc 2011, 111:1670-1673.

34. Kasarskis EJ, Berryman S, Vanderleest JG, Schneider AR, McClain CJ: Nutritional status of patients with amyotrophic lateral sclerosis: relation to the proximity of death. Am J Clin Nutr 1996, 63:130-137.

35. Vaisman N, Lusaus M, Nefussy B, Niv E, Comaneshter D, Hallack R, Drory VE: Do patients with amyotrophic lateral sclerosis (ALS) have increased energy needs? J Neurol Sci 2009, 279:26-29.

36. Hoit JD, Lansing RW, Dean K, Yarkosky M, Lederle A: Nature and evaluation of dyspnea in speaking and swallowing. Semin Speech Lang 2011, 32:5-20.

37. Schols A, Mostert R, Cobben N, Soeters P, Wouters E: Transcutaneous oxygen saturation and carbon dioxide tension during meals in patients with chronic obstructive pulmonary disease. Chest 1991, 100:1287-1292

38. Wolkove N, Fu LY, Purohit A, Colacone A, Kreisman H: Meal-induced oxygen desaturation and dyspnea in chronic obstructive pulmonary disease. Can Respir J 1998, 5:361-365.

39. Siirala W, Olkkola KT, Noponen T, Vuori A, Aantaa R: Predictive equations over-estimate the resting energy expenditure in amyotrophic lateral sclerosis patients who are dependent on invasive ventilation support. Nutr Metab (Lond) 2010, 7:70

40. Gonzalez-Bermejo J, Lofaso F, Falaize L, Lejaille M, Raphael JC, Similowski T, Melchior JC: Resting energy expenditure in Duchenne patients using home mechanical ventilation. Eur Respir J 2005, 25:682-687.

41. Lechtzin N, Scott Y, Busse AM, Clawson LL, Kimball R, Wiener CM: Early use of non-invasive ventilation prolongs survival in subjects with ALS Amyotroph Lateral Scler 2007, 8:185-188.

42. Leonardis L, Dolenc Groselj L, Vidmar G: Factors related to respiration influencing survival and respiratory function in patients with amyotrophic lateral sclerosis: a retrospective study. Eur J Neurol 2012, 19:1518-1524.

doi:10.1186/1471-2466-14-17

Cite this article as: Georges et al:: Noninvasive ventilation reduces energy expenditure in amyotrophic lateral sclerosis. BMC Pulmonary Medicine 2014 14:17.

\section{Submit your next manuscript to BioMed Central and take full advantage of:}

- Convenient online submission

- Thorough peer review

- No space constraints or color figure charges

- Immediate publication on acceptance

- Inclusion in PubMed, CAS, Scopus and Google Scholar

- Research which is freely available for redistribution 